\title{
Tsafon
}

Revue d'études juives du Nord

$72 \mid 2016$

Juifs, Israéliens, dans la littérature française et israélienne

\section{Ewa Tartakowsky, Les Juifs et le Maghreb. Fonctions sociales d'une littérature d'exil}

\section{Françoise Marti}

\section{CpenEdition}

\section{Journals}

Édition électronique

URL : https://journals.openedition.org/tsafon/490

DOI : $10.4000 /$ tsafon.490

ISSN : 2609-6420

Éditeur

Association Jean-Marie Delmaire

Édition imprimée

Date de publication : 1 décembre 2016

Pagination : 180-182

ISSN : $1149-6630$

Référence électronique

Françoise Marti, «Ewa Tartakowsky, Les Juifs et le Maghreb. Fonctions sociales d'une littérature d'exil », Tsafon [En ligne], 72 | 2016, mis en ligne le 31 mai 2018, consulté le 29 juin 2021. URL : http:// journals.openedition.org/tsafon/490 ; DOI : https://doi.org/10.4000/tsafon.490

Ce document a été généré automatiquement le 29 juin 2021.

Tsafon. Revues d'études juives du Nord 


\title{
Ewa Tartakowsky, Les Juifs et le Maghreb. Fonctions sociales d'une littérature d'exil
}

\author{
Françoise Marti
}

\section{RÉFÉRENCE}

Ewa Tartakowsky, Les Juifs et le Maghreb. Fonctions sociales d'une littérature d'exil, Tours, Presses universitaires François-Rabelais, Collection « Migrations », 2016, 330 p., $18 €$.

1 Issu d'un travail de recherche doctoral, l'ouvrage se donne pour tâche de cerner si un déracinement favorise des vocations littéraires, l'exil constituant une expérience fondatrice d'appartenance identitaire et l'écriture pouvant constituer une thérapie contre la nostalgie et un point d'appui pour l'adaptation à la nouvelle situation. À cette fin, l'auteure oriente sa réflexion vers les rapports entre fictionnel et existentiel, en direction du groupe exilé et de la collectivité d'accueil, et sonde les approches tant historiques que littéraires chez les écrivains juifs d'origine maghrébine.

2 Mais tout d'abord, il s'agit de vérifier si la littérature peut constituer un objet d'étude pour le sociologue, et d'autre part si l'étude sociologique est pertinente pour l'analyse de faits littéraires, mais aussi d'examiner le choix du terme "exil » par rapport à d'autres (migration, immigration, émigration, asile politique, diaspora...). L'étude porte exclusivement sur des auteurs d'origine judéo-maghrébine ayant connu eux-mêmes un déplacement et écrivant en français.

Dans une analyse extrêmement documentée, l'auteure dégage les conditions d'émergence d'une littérature d'exil pour ces exilés judéo-maghrébins. C'est ainsi qu'après avoir souligné la position très particulière des Juifs du Maghreb, souvent francophones et francophiles, elle met à jour l'évolution de la conscience juive (" réveil juif») après la Guerre des Six jours en 1967, provoquant une "différenciation identitaire » de plus en plus marquée. À cette sensibilisation, s'ajoute un changement 
de perception de l'histoire dans les années 1980, auquel contribuent les procès en relation avec la Shoah et les recherches sur cette période, conduisant au fait que le génocide devient le paradigme de toutes les mémoires douloureuses. C'est forte de ces prises de conscience que la littérature prend en charge la mémoire de l'exil des Juifs d'Afrique du Nord, en se situant au sein des littératures "postcoloniales", sur lesquelles la pensée d'Édouard Saïd a exercé une influence sensible.

Examinant ensuite la littérature judéo-maghrébine d'expression française, l'auteure montre que ce n'est qu'au xix siècle qu'apparaît en Tunisie le récit fictionnel en français, suivi très tôt par d'autres au Maroc et en Algérie (Sadia Levy, Jacques Vehel, Elissa Rhaïs...) qui publieront jusqu'à la Seconde Guerre mondiale. Puis une autre génération (Albert Memmi, Jean Daniel, Albert Bensoussan, Jeanne Benguigui...) publie dans les années 1950 avant l'exil massif. Mais c'est sur les auteurs exilés venus en France que porte l'étude (109 auteurs dont $45 \%$ originaires d'Algérie) afin de tenter de dégager dans quelle mesure un déplacement géographique « travaille » les créateurs.

5 Et de fait, l'auteure constate que $77 \%$ d'entre eux consacrent leur premier ouvrage à l'exil. L'étude des titres et du paratexte dégage les thèmes dominants : exil, Maghreb, histoire/mémoire, identité juive.

6 Le regard porté sur ces œuvres révèle l'attachement des écrivains (Albert Memmi, Nine Moati, Gil Ben Aych, Colette Fellous, Pol-Serge Kakon...) à décrire la vie quotidienne familiale, le quotidien de la communauté, les détails des vêtements, du folklore, des fêtes, et à restituer ainsi l'ambiance, l'atmosphère des quartiers en faisant appel à une mémoire sensorielle. Mais l'histoire peut être également source d'inspiration, même quand elle est mythique : c'est ainsi que le personnage de la Kahena inspire un certain nombre d'œuvres (Gisèle Halimi, P.-S. Kakon, Didier Nebot), de même que s'élabore la mémoire plus ou moins mythique de la coexistence harmonieuse entre Juifs et Musulmans, cependant que l'arrivée en France fait l'objet d'un désenchantement après avoir été, au Maghreb, objet de fascination pour ses idéaux émancipateurs dont ont bénéficié, depuis la Révolution, les Juifs de métropole. Cette représentation mythifiée de la France est écornée tout d'abord en 1940 avec l'abrogation du décret Crémieux en Algérie, puis véritablement ébranlée lors de l'arrivée en France, où les exilés se heurtent à l'ethnocentrisme culturel des Occidentaux et même des Juifs ashkénazes. Assimilés aux Pieds-Noirs ou aux Arabo-Musulmans, les Juifs du Maghreb se trouvent confrontés à un problème identitaire qui les poussera à se reconnaître dans la mémoire de la Shoah : elle leur procure une validation d'appartenance à la spécificité culturelle juive, et, de là, leur permettra de se revendiquer comme "séfarades", terme quasiinemployé jusque-là. Cette revendication pousse les écrivains à redécouvrir la « langue perdue ", la tradition orale des communautés juives du Maghreb, une langue populaire teintée d'arabe ou de judéo-arabe, un style (le pataouète pour l'Algérie), une langue que, dans leur "drame linguistique» (Memmi), ils considèrent comme leur langue maternelle alors même qu'ils s'expriment et écrivent en français.

7 Après avoir analysé les conditions d'émergence et les caractéristiques de ces littératures, la chercheuse aborde ensuite la question des fonctions sociales de cette littérature d'exil. La première de ces fonctions est mémorielle. Outre que se souvenir est de toute façon important dans la tradition juive, deux processus sont à l'œuvre ici : un processus de remémoration sur le plan individuel, et un processus de mémorialisation sur le plan collectif. Cet acte de mémoire a pour fonction d'amplifier et de consolider la sociabilité des membres du groupe, mais aussi de créer des 
passerelles entre émotions passées et présentes. On peut donc considérer la littérature comme un médium mémoriel de transmission.

Une deuxième fonction de cette littérature d'exil est historiographique. Alors que les Juifs ashkénazes ont commencé à élaborer leur histoire dès le xvIII siècle sous l'impulsion de la Haskalah et à utiliser des méthodes scientifiques avec la Wissenschaft des Judentums dans un but émancipateur, l'historiographie des Juifs du Maghreb n'émerge que vers 1860 , surtout élaborée par des Juifs européens, et ce n'est qu'à la fin de la période coloniale que commence à se mettre en place une historiographie plus scientifique, avec en particulier l'ouvrage d'André Chouraqui : Marche vers l'Occident. Les Juifs d'Afrique du Nord (1952). C'est pourquoi l'on peut dire que la littérature judéomaghrébine d'expression française devance la production historiographique en répondant à une demande de reconnaissance d'un passé jusque-là ignoré ou gommé, et en contribuant à la patrimonialisation de ce passé, l'intégrant ainsi dans la mémoire nationale.

9 Enfin, la troisième fonction de ces écrits d'exil est une fonction d'adaptation. La réalité qu'elle donne à lire est destinée aux deux groupes: la communauté d'exil et la communauté d'accueil, faisant des écrivains de véritables "passeurs culturels » qui croisent les héritages sans se contenter de les juxtaposer ni surtout de les mettre en concurrence, contribuant ainsi au métissage social.

$10 \mathrm{Au}$ terme de son parcours, la chercheuse peut conclure que l'expérience de l'exil joue un rôle déterminant dans l'entrée en littérature. Elle élargit cette observation à d'autres littératures d'exil, comme celle de la diaspora indienne anglophone pour laquelle de nombreux exemples sont cités, à l'instar des exemples et citations très abondants de romans d'auteurs judéo-maghrébins qui illustrent la démonstration, œuvres rappelées dans une bibliographie pléthorique à la fin de l'étude. 